\title{
Recognition of Foreign Qualifications \\ Celebrates Higher Education \\ Collaboration Too
}

\author{
Jenneke Lokhoff
}

International higher education collaboration and recognition of foreign qualifications have been inseparable from the very start. The institutionalization of higher education collaboration after the Second World War, when international organizations such as IAU were founded, also marked the start of the institutionalization of recognition of foreign qualifications.

This piece celebrates seventy years of IAU by reflecting on the past, present and future of academic recognition of foreign qualifications, as one of the elements of internationalization that facilitate and validate international student mobility. It will do so by providing snapshots from some milestones in the field. The perspective taken is based on the experiences of Nuffic, which was founded only two years after IAU, in the same spirit of international cooperation in education. Nuffic was tasked with the recognition of foreign qualifications in 1958.

\section{The History of Recognition, a History of Student Mobility}

How did the field develop in those early decades? From the end of the Second World War to the mid-1970s, student mobility between countries was limited to those that qualified for one of the few scholarships available or were able to finance the experience themselves. The low mobility rate resulted in few evaluations, but this would gradually change, as would the attitude towards recognition. The 1980s and especially the 1990s would see developments that would lay the foundation of current recognition practices.

\footnotetext{
J. Lokhoff $(\bowtie)$

Nuffic, The Hague, The Netherlands

e-mail: jlokhoff@nuffic.nl

(C) The Author(s) 2021 


\section{The First Decades: Evolving Attitudes}

After the Second World War, attitudes towards recognition favoured "equivalence". This aimed to match components of one foreign programme with every component in a receiving country's programme. In other words, a foreign degree had to be identical or almost identical to be recognised.

This attitude shifted towards "recognition" out of necessity from increased student mobility in the 1980s. A degree no longer had to be identical but could be recognised according to the purpose for which recognition was sought. The foreign degree sufficed if assessed at a comparable level with comparable functions, even though it may differ in detail.

When internationalization really took off in the 1990s, a new approach gained ground that is still used today: "acceptance". Under this precept, a foreign qualification deemed slightly inferior to the nearest comparable degree in the receiving country, would be accepted at that level. Small differences could be softened and degrees still accepted because of the enrichment that a different educational approach can bring to the host society. Denial of recognition occurred only when differences were too substantial.

This principle of 'acceptance while respecting the differences' prevails today - reflected in the General Directives for professional recognition of the European Union and the Lisbon Recognition Convention of the Council of Europe/UNESCO. Mutual trust in each other's education system, as a result of growing mobility and the increase of information on the different systems, made this change of attitude possible.

During this time, attitudes also changed in the workplace. After a "royal" start in an actual palace (and the current work palace of the King of The Netherlands), Nuffic moved to the former hotel "Wittebrug" in 1978. Into the 1990s, Nuffic's credential evaluation team made their home in a spacious attic - stuffed with reference books and university catalogues from across the globe. The space was filled with cigarette smoke and a team whose members subtly rivaled to show their erudition. Pride and effort went into the style and language used to write the statement. Recognition was considered a serious intellectual exercise, and the ambiance described by some as rebellious, yet still cozy or "gezellig": every day featured a collective tea break at 16:00.

Nuffic's "epic stories from the attic" capture a scene in stark contrast with today's workplace. Though still amiable and intellectual, Nuffic now has flexible workspaces, clean desk policies and efficiently processes a high number of evaluations. Evaluation time dropped from three days to $30 \mathrm{~min}$ on average - a high(er) level of efficiency aided not only by modern communication and digitalization, but also new developments that refined modern recognition practices in the 1980s and 1990s.

\section{Towards a Legal Framework Based on Burden of Proof}

In the early days, the international community worked towards creating a legal framework for the recognition of foreign qualifications. The first conventions emerged in 
the 1950s. Later in the 1970s, UNESCO launched regional conventions including Latin America and the Caribbean (Mexico City, 1974), Arab States (Paris, 1978), European region (Paris, 1979), the African region (Arusha, 1981), and Asia and the Pacific (Bangkok, 1983).

At the time of these conventions, educational systems of signatory countries in Europe were still quite comparable. But over time, the diversification in higher education systems and expanding signatories showed the limits of these conventions. These developments led to a new UNESCO/CEPES and Council of Europe treaty: The Lisbon Recognition Convention (LRC) of 1997.

The LRC adopted a new positive attitude of acceptance, as mentioned above. The core was to emphasize the principle of fair and transparent recognition procedures, and the acknowledgement that differences should be accepted unless substantial differences were detected. The Convention also created the LRC Committee Bureau to oversee operations and tasked the European National Information Centres (ENICs) with the implementation of the Conventions' principles.

\section{Networks and Peer Collaboration}

In the 1980s/1990s, a second fundamental element for recognition emerged: the institutionalization of collaboration between national information centres. In 1984, the predecessor of the European Union created the National Academic Recognition and Information Centres (NARIC network), while in 1994 the NEIC (the National Education Information Centres) network transformed into the afore-mentioned European National Information Centre (ENIC) Network from UNESCO and the Council of Europe.

The importance of the Networks is their provision of an operational structure for recognition. The LRC tasks ENICs with providing information about their countries education system as well as treaty implementation in the national context. The two Networks work closely together to solve recognition issues, and in practice, they overlap; each NARIC Centre is also the ENIC Centre.

In the early days, discussions on "methods and techniques" contributed to the text of the LRC. Good practice was also developed in working groups from the Council of Europe/UNESCO and through structural project funding from the European Commission. Centres collaborated with other stakeholders in higher education - institutions, students, quality assurance and communities such as the European Association for International Education.

Peer collaboration also resulted in capacity building, such as the establishment of NARICs in the future members of the European Union through the PHARE programme. Nuffic offered support and, small in terms of number of staff but large in terms of means - the experts always travelled with two extra suitcases filled with reference books, including the voluminous IAU International Handbook of Universities. These were truly pre-digital times.

The Network's joint annual meeting is the highlight for networking, debate, and sharing expertise, giving members a robust and effective operational structure to further develop recognition. For a full understanding, it is important to note that 
recognition is organized differently in each LRC Treaty country, and each ENICNARIC has a different remit and size.

\section{Political Collaboration}

The third and final pillar for recognition was developed in the 1990s and culminated in the launch of the Bologna Process to create the European Higher Education Area in 1999. The Bologna Process placed recognition of foreign qualifications at the heart of its agenda and supported recognition through comparability and compatibility of higher education systems.

The harmonization efforts towards a three-cycle structure across the EHEA facilitated the recognition of qualifications on the system level. The political commitment to the process pushed the development of various instruments and tools serving recognition, such as the Diploma Supplement, the European Credit Transfer Accumulation System and qualification frameworks. The shortness of this paragraph is evidently inversely proportional to the significance of "Bologna" for recognition within Europe!

\section{Recognition at Present}

What is the present state of play for recognition? There is an ongoing increase in student mobility and digital solutions, and both are shaping recognition along the lines of the framework established in the 1980s/1990s; the international legal framework has been further strengthened and innovated. While major steps were taken in the previous decade, there are still challenges in regards to the implementation of fair recognition, notably on the practical and institutional level, where further collaboration would be desirable.

\section{Student Mobility, Digitization and Efficiency}

Since the millennium, global student mobility has tripled and directly impacted credential evaluation as a process and profession. The higher volume of international students has driven demand for more evaluations and has accelerated efforts to innovate and optimize the process, especially in high volume countries.

The late 1990s saw the introduction of computers and the internet, and this enabled unprecedented access to evaluation information. The first databases reduced processing times and increased the consistency of decisions. Statements could be made in digital layout with block texts focused on key information. This was a world apart from the eloquently written epistles of the 1980s. Another aspect was the possibility for national information centres to provide information to its stakeholders.

The new modes of communication also drove international collaboration. Email became the standard, allowing for a fast and easy exchange of information. 


\section{International Framework}

Globally, different regions have been pushing fair "recognition" forward. The creation and adoption of the "Global Convention on the Recognition of Qualifications concerning Higher Education" in November 2019, formulated a number of general criteria to promote the fair and smooth recognition of diplomas worldwide. This Convention's novelty was a clear definition of substantial differences.

In recent years, several UNESCO regions have introduced a new generation of regional conventions that describe the principles of fair recognition, and these currently experience a momentum. Recently, the Asia and Pacific (Tokyo 2011) and African region (Addis Ababa 2014) entered into force with Latin America and the Caribbean (Buenos Aires 2019) expected to follow in the near future.

Following ratification of the Tokyo Convention, the Asian Pacific region has moved towards operationalizing recognition through the establishment of the "AsiaPacific Network of National Information Centres" (APNNIC). The Association of Southeast Asian Nations (ASEAN) has initiated several initiatives to support the recognition of foreign qualifications in their region, including qualification frameworks and a credit transfer system. We also see advances towards inter-regional collaboration between the ENIC-NARIC and APNNIC Networks, which is a welcome development in information provision due to the ever-increasing number of global students. This also signals the importance of (operationalizing) the regional conventions in offering support for a successful implementation of the Global Recognition Convention.

In the European Higher Education Area, there is a focus on automatic recognition at the system level and further implementation of the LRC, supported by the European Commission that made automatic recognition a priority within their ambition to create a European Education Area by 2025 .

One of the LRC's challenges -and possibly other regional conventions' tooremains a shared understanding of the principles by all competent authorities. Inclusion in law does not mean that legal principles are implemented at the practical level. Here there is still enormous work to be done. Collaboration between national information centres and the higher education institution community will be essential for building a shared understanding of implementation on a practical level.

\section{3 "We Can Only See a Short Distance Ahead, But We Can See Plenty There That Needs to Be Done." - Allan Turing}

What does the future hold for foreign qualifications recognition of? While this may be unknown, it merits highlighting student mobility trends, the expansion of the legal framework, flexibilization of education and digitalization of student data. 


\section{Asia-Pacific in the Lead?}

Student mobility trends predict a continued increase in international students in the coming decades. Whereas the majority of international students currently study in North America and Europe, some predict other regions such as Asia will assume a larger, perhaps even the largest share of international students in the future. This underscores the need for smooth and fair recognition, both regionally and globally.

\section{International Legal Framework}

The UNESCO conventions provide a robust legal framework for recognition. However, judging from current experience, their implementation - especially on a practical level - depends on how the Global Convention and regional conventions are translated into action and rendered operational; their success also depends on the extent of political support available for facilitating fair recognition.

At the time of writing, the COVID-19 crisis had only just begun to impact education, international student mobility and, consequently, recognition of foreign qualifications. Even when student mobility numbers rise again, the aspect of fair recognition during this period may continue to be a daunting process. International collaboration will be the key for fair recognition of learning experiences, and could also serve future global student mobility.

\section{Flexibilization of Education}

Another trend impacting the future is the changing education landscape itself with an increase in standalone learning units. While this phenomenon existed previously, institutions are adopting and creating flexible learning paths at a hitherto unseen pace. Before the COVID-19 pandemic, digital solutions were a catalyst for the delivery of education "units" online (e.g. MOOC type solutions), that resulted in microcredentials.

The flexibilization and stacking of credits create opportunities - and along with these, fundamental questions for recognition. Opportunities exist for applicants using these standalone credits to fill gaps in their experience. But, using the current methodology, a stack of credits that match the workload may not necessarily lead to recognition when a coherent profile is missing. A profile is part of any degree and describes the purpose and content of a programme. If stacking takes off, how are these experiences validated within the current methodology? This will need to be further explored so that we can ensure fair recognition of these experiences.

\section{Digitalization of Student Data and Recognition}

Recognition may be on the eve of another major development with the promulgation of digital solutions for the field. The transformative impact of digital communication and infrastructure on recognition, begun in the 1990s, continues to drive innovation in areas of digitalization of student data, such as diplomas, transcripts and personal 
information. This takes place against the backdrop of digitalization of other relevant information, such as the unique identifiers of HEIs in the IAU World Higher Education Database, the Global WHED ID.

The digital exchange of student data offers potential opportunities for recognition, for example, in terms of efficiency, consistency, verification and reliability. Yet, some effort will have to be made to reap the benefits. Within ENIC-NARIC Networks, collaboration between the Groningen Declaration Network and EMREX takes digitalization further, and ASEAN are exploring possibilities for its own region as well. Points of attention include standardization, both at the level of data format and content. Solutions will ideally involve both recognition practitioners, technicians and other end users (qualification holders, institutions and credential evaluators) to achieve innovative solutions.

The expectation is that we will see the transformation of credential evaluation as a profession in the near future, through digitalization and automating steps of the evaluation process. This will be even more so the case when higher levels of data maturity - such as machine-readable data - will become operational, and a higher level of standardization of the data content has been reached. This, obviously, requires international collaboration.

\section{CONGRATULATIONS IAU!}

If anything, this piece wishes to contribute to the celebration of 70 years of IAU from the perspective of recognition. Both IAU and Nuffic embarked on their respective journeys together and, looking ahead, we will have plenty - if not more - to work on as we work supporting higher education around the globe. But for now, congratulations!

Jenneke Lokhoff is senior policy officer at Nuffic, the Netherlands organization for internationalization in education, home to the Dutch ENIC-NARIC. She has been project lead for numerous international recognition projects. She currently serves as President of the ENIC-NARIC networks.

Open Access This chapter is licensed under the terms of the Creative Commons Attribution 4.0 International License (http://creativecommons.org/licenses/by/4.0/), which permits use, sharing, adaptation, distribution and reproduction in any medium or format, as long as you give appropriate credit to the original author(s) and the source, provide a link to the Creative Commons license and indicate if changes were made.

The images or other third party material in this chapter are included in the chapter's Creative Commons license, unless indicated otherwise in a credit line to the material. If material is not included in the chapter's Creative Commons license and your intended use is not permitted by statutory regulation or exceeds the permitted use, you will need to obtain permission directly from the copyright holder.

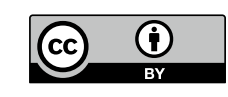

